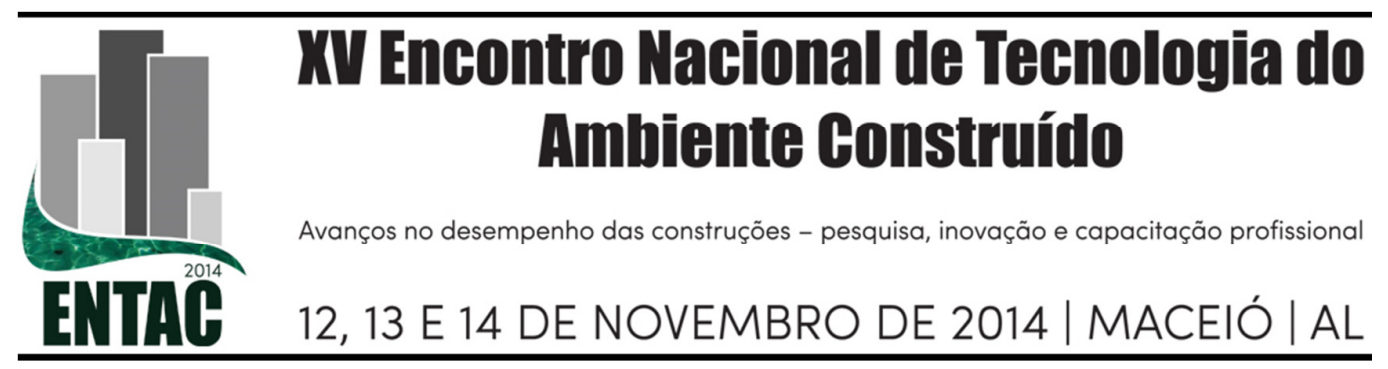

\title{
INFLUÊNCIA DE ADITIVO RETARDADOR DE PEGA NA PASTA DE GESSO COM RESÍDUO DE GESSO CALCINADO
}

\author{
MESQUITA, Luis Sérgio Polimeni (1); PÓVOAS, Yêda Vieira (2).
}

(1) Universidade de Pernambuco. E-mail: luis.sergio2@ @otmail.com; (2) Universidade de Pernambuco.

E-mail: yeda.povoas@gmail.com

\begin{abstract}
RESUMO
A utilização do gesso na construção civil vem tendo um crescimento exponencial devido a sua alta qualidade, baixo custo e facilidade de manuseio. Durante sua aplicação existe a geração de grande quantidade de resíduo, e por consequência, um acréscimo de custo devido à necessidade de descarte adequado. O objetivo desta pesquisa é estudar uma forma de reaproveitamento deste resíduo na própria obra, calcinando-o e realizando sua mistura com pasta de gesso e retardador de pega (citrato de sódio), visando verificar as alterações que ocorrem em suas propriedades mecânicas e no tempo de utilização, buscando a redução de custos com o descarte e a minimização do impacto ambiental. Como metodologia, o gesso e o resíduo foram caracterizados de acordo com os ensaios recomendados pela NBR 13207 (ABNT, 1994) e, utilizando-se um calorímetro de condução isotérmica, foram avaliados os tempos de pega e o tempo de utilização, por meio do calor de hidratação. Para tanto, houve substituição do gesso (em porcentagem de massa) por resíduo de gesso calcinado nas proporções 0, 10, 50, 90 e 100\%, utilizando-se citrato de sódio na proporção de $0,06 \%$ em relação aos materiais secos. $\mathrm{O}$ beneficiamento do resíduo foi feito através da moagem, peneiramento, retificação da sua composição granulométrica e calcinação a $150^{\circ} \mathrm{C}$ pelo período de uma hora. A fim de reduzir o resíduo depositado no meio ambiente e poupar a matéria prima que é esgotável, os resultados indicam a possibilidade de se utilizar a mistura com $50 \%$ de resíduo e $0,06 \%$ de citrato de sódio.
\end{abstract}

Palavras-chave: Gesso, Reciclagem, Retardador de pega, Calor de hidratação.

\begin{abstract}
The use of gypsum in construction presents an exponential growth because of its high quality, low cost and easy handling. During the application there are large amount of waste generated, and consequently, the cost grows due to the need for appropriate disposal. This research aims to study a form to reuse the plaster waste at the construction site. The calcination of the residue and the mixture with the plaster was done using or not the setting retardant (sodium citrate) to verify the changes in the mechanical properties and the handle time, seeking to reduce cost of disposal and minimization of environmental impact. For this, the plaster and the residue were characterized according to the tests recommended by the NBR 13207 (ABNT, 1994). It was used, also, an isothermal calorimeter conduction to study the setting time and the handle time by the heat hydration. For this purpose, the gypsum was replaced (in mass\%) of calcined plaster residue in the proportions: 0, 10, 50, 90 and 100\%, using sodium citrate at a ratio of $0.06 \%$ relative to dry materials. The residue was milled, sieved, and the granulometric composition was done. Afterwards it was calcined at $150^{\circ} \mathrm{C}$ for a period of one hour. To reduce the waste deposited on the environment and save the gypsum which is exhaustible, the results indicate the possibility of using the plaster with $50 \%$ of residue and $0.06 \%$ of sodium citrate.
\end{abstract}

Keywords: Gypsum, Recycling, Setting Retardant, Heat of hydration. 


\section{INTRODUÇÃ̃O}

O crescimento econômico experimentado pelo País nos últimos 15 anos teve como um de seus alicerces a construção civil. Em 2011, o setor representou 5\% do PIB, ultrapassando pela primeira vez os $\mathrm{R} \$ 200$ bilhões de faturamento. No entanto, nem sempre foi tão bem assim. O setor passou por um período de recessão. A partir de meados do ano 2000, o cenário começou a mudar. O aumento da renda da população e iniciativas públicas como o Minha Casa Minha Vida também tiveram sua influência. Nos últimos quatro anos a construção civil brasileira viveu um dos melhores momentos de sua história. São Paulo, que tem um dos $\mathrm{m}^{2}$ mais caros da América Latina, apresenta valorização anual de quase $20 \%$. Para 2014, a previsão é que o país cresça $2,5 \%$ e com isso a construção civil atinja o crescimento de $2 \%$, segundo o Sinduscon-SP (AYRES, 2013).

Com toda a agitação do mercado para construir e vender começou a existir a preocupação em utilizar materiais mais baratos e com uma maior facilidade de aplicação. Nesse aspecto o gesso destacou-se, pois ele é visto como uma excelente alternativa para as construtoras, devido a sua alta qualidade, seu baixo custo, e sua facilidade de manuseio, assim gerando uma maior produtividade por parte dos aplicadores.

O Brasil está entre os 10 maiores produtores de gesso mundial. Em 2012 foi produzido 3,7 milhões de toneladas no país, que representa $2,5 \%$ da produção mundial. Da produção de gesso natural brasileira, $89,5 \%$ é produzida na região do Araripe, em Pernambuco. O polo gesseiro oferece cerca de 13.200 empregos diretos e aproximadamente 60.000 indiretos, e possui um faturamento anual de US\$ 364 milhões/ano (DNPM, 2013).

Devido a esse aumento no setor, houve um aumento substancial na geração de resíduos em obras, em especial do gesso, pois sua alta velocidade de endurecimento e a falta de capacitação aos profissionais que trabalham com o produto acarretam em um grande desperdício. Estima-se que o índice de desperdício seja de $45 \%$ do gesso utilizado (GUSMÃO, 2008). Esse gasto exagerado leva ao aumento considerável do custo, já que o descarte necessita de um local adequado para que não contamine o solo. Em Recife o gesso corresponde a $4 \%$ do volume de resíduo da construção civil, cerca de $50 \mathrm{~m}^{3}$ diários (RIBEIRO et al., 2013).

Em 2011, por meio da resolução $\mathrm{N}^{\circ}$ 431, o CONAMA reclassificou o gesso como resíduo de classe $\mathrm{B}$, significando que ele pode ser reciclado para outras destinações. Com o intuito de diminuir os gastos com a destinação adequada dos resíduos e de proteger o meio ambiente, se faz necessário o estudo de formas de reutilizar e reciclar resíduos dentro da construção civil.

Esta pesquisa tem por objetivo avaliar a influência do retardador de pega - citrato de sódio, na pasta de gesso com resíduo de gesso calcinado.

\section{REVISÃO BIBLIOGRÁFICA}

A geração de resíduo de gesso vem sendo motivo de várias pesquisas nos últimos anos. Esta pesquisa tem como base os estudos de Schmitz; Póvoas (2009), Cavalcanti et al. (2012), Pinheiro (2011) e Alves et al. (2012).

Na pesquisa de Schmitz; Póvoas (2009) foi adicionado o resíduo com dimensão máxima de $0,6 \mathrm{~mm}$ nos teores de $0 \%, 5 \%$ e $10 \%$ à pasta de gesso destinada ao revestimento 
interno de parede e verificou-se por meio de vários ensaios um resultado positivo no desempenho geral do material. No entanto, houve uma considerável redução no tempo útil de aplicação deste revestimento.

Segundo Pinheiro (2011), a reciclagem é um conjunto de processos, onde ocorre a moagem, a retificação granulométrica e a calcinação. Cavalcanti et al. (2012) constatou que a composição granulométrica do resíduo interfere nas características físicas e mecânicas da pasta de gesso. Ao fim deste estudo foi verificado que uma composição granulométrica uniforme obteve os melhores resultados.

Para a calcinação, Pinheiro (2011) submeteu o resíduo de gesso produzido em laboratório à desidratação em diferentes temperaturas e tempos. Foram adotadas as seguintes temperaturas para análise das condições de calcinação do resíduo de gesso, $120^{\circ} \mathrm{C}, 150^{\circ} \mathrm{C}$ e $200^{\circ} \mathrm{C}$ e os tempos de permanência de $1,2,5,8,16$ e 24 horas, recuperando parte de suas propriedades físicas e mecânicas, voltando a sua forma comercial. A autora conclui que o resíduo de gesso na construção civil pode ser utilizado em larga escala, com a ressalva de que não pode haver contaminação em excesso.

Diversas pesquisas sobre a adição de aditivo retardador de pega na pasta de gesso vêm sendo desenvolvidas com o intuito de aumentar o período de aplicação do revestimento, a fim de diminuir a produção de resíduo.

Alves et al. (2012) estudaram a interferência do citrato de sódio no calor de hidratação da pasta de gesso. Eles observaram como se apresentou o tempo útil para as amostras que utilizaram $0,00 \%, 0,02 \%, 0,04 \%, 0,06 \%$ e $0,08 \%$ do citrato em relação à massa do gesso. Neste, constatou-se as alterações na calorimetria de hidratação e na resistência à compressão. Mostrou que o teor de $0,06 \%$ de citrato de sódio é o mais indicado.

Cincotto; Hincapié (1997) estudaram várias substâncias químicas retardadora dos tempos de início e fim de pega, tais como, ácido cítrico, citrato de sódio, acetato de sódio, bórax, ácido tartárico, hexametafosfato de sódio, fosfato de amônio, fosfato de potássio, caseína e peptona. O citrato de sódio, o bórax, os fosfatos e a peptona apresentaram os melhores resultados. Verificou-se ainda que todas as amostras que utilizaram aditivo retardador de pega tiveram um decréscimo da dureza quando comparadas às amostras sem utilização de aditivos. Em relação à resistência à compressão, a NBR 13207 (ABNT, 1994) recomenda que o gesso atinja no mínimo 8,4 $\mathrm{MPa}$. As únicas amostras que não alcançaram o valor mínimo sugerido pela norma foram as que utilizaram o ácido tartárico, o acetato de amônio e as que utilizaram o teor de $2 \%$ de acetato de sódio.

Cincotto; John (2010) agruparam os aditivos retardadores de pega em três categorias, conforme o seu modo de atuação: espécies químicas que diminuem a velocidade de dissolução do hemidrato, espécies químicas que geram reações complexas e produtos orgânicos de massa molecular elevada. Os aditivos, de modo geral, influenciam em várias propriedades da pasta do gesso. Neste estudo chamou-se a atenção para dois fenômenos em particular: a expansão entre as partículas e a porosidade entre elas.

Ribeiro et al. (2013) estudou a viabilidade técnica para se obter gesso beta a partir de resíduos de revestimento de parede e instalação de forro. Concluiu-se que os dois tipos de gesso reciclado satisfizeram a resistência à flexão exigida pela NBR 12775 (ABNT, 1992); a resistência à compressão e a dureza encontrada foi satisfatória quando utilizado resíduo de placa e de revestimento. Houve a ressalva de que se devem realizar testes em escala industrial como passo decisivo para definir a tecnologia adequada para permitir a 
utilização do resíduo de gesso como material de construção, o que trará uma contribuição à indústria quanto à questão econômica, financeira e ambiental.

\section{MATERIAIS E MÉTODOS}

O gesso utilizado na pesquisa foi obtido no mercado. Como o objetivo é reaproveitar o resíduo na própria obra, sua coleta foi feita em visita única.

Para iniciar o estudo houve o beneficiamento do resíduo. O mesmo passou por um moinho, especialmente construído para este fim, por duas vezes (Figura 1). Como foi seguida a proposta de composição granulométrica de Cavalcanti et al. (2012) (Quadro 1), realizou-se o peneiramento. Posteriormente o resíduo foi calcinado em estufa a $150^{\circ} \mathrm{C}$ por 1 hora, seguindo os estudos de Pinheiro (2011). Todos os processos foram realizados em laboratório.

Figura 1 - Moinho

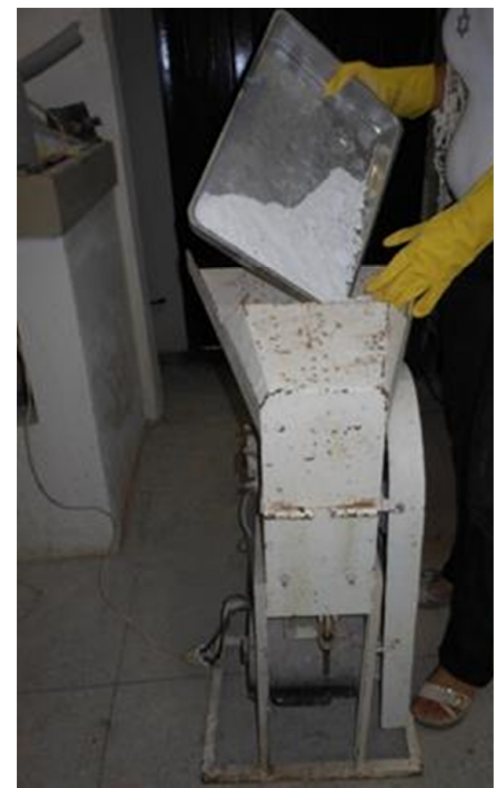

Quadro 1 - Composição granulométrica do resíduo de gesso

\begin{tabular}{|c|c|c|}
\hline Abertura de peneira $(\mathbf{m m})$ & \% Retido & \% Retido acumulado \\
\hline 0,075 & 0,50 & 0,50 \\
\hline 0,105 & 1,00 & 1,50 \\
\hline 0,210 & 1,50 & 3,00 \\
\hline 0,300 & 18,00 & 21,00 \\
\hline 0,420 & 27,00 & 48,00 \\
\hline 0,600 & 21,00 & 69,00 \\
\hline 0,840 & 19,00 & 88,00 \\
\hline 1,200 & 12,00 & 100,00 \\
\hline TOTAL & 100,00 & 100,00 \\
\hline
\end{tabular}


O resíduo calcinado foi previamente misturado ao gesso antes de entrar em contato com a água, que foi destilada. A relação água/materiais secos utilizada foi de 0,6 . O gesso foi substituído pelo resíduo calcinado nas proporções de $0 \%, 10 \%, 50 \%, 90 \%$ e $100 \%$, em massa. O procedimento de mistura realizado foi o recomendado pela MB 3469 (ABNT, 1991).

Na primeira etapa da pesquisa foram realizados ensaios para a caracterização do gesso e do resíduo, definindo-se assim: as características físicas do pó, obedecendo ao método de ensaio da MB 3468 (ABNT, 1991) e as características físicas e mecânicas das misturas de gesso e resíduo com e sem a utilização de retardador de pega, segundo a MB 3469 e MB 3470 (ABNT, 1991), respectivamente.

Para determinar a resistência à compressão e a dureza, foram moldados três corpos de prova para cada mistura, conforme indicação da MB 3470 (ABNT, 1991). Antes de romper os corpos de prova à compressão, a dureza foi determinada por meio de um durômetro Shore $\mathrm{C}$, utilizando a média do valor encontrado em 3 faces de cada corpo de prova, tomando-se o cuidado de não utilizar a face de moldagem.

Utilizando um calorímetro pseudoadiabático, obteve-se a curva do calor de hidratação em função do tempo, onde foram medidos os tempos de pega das amostras. $\mathrm{O}$ tempo de início de pega foi caracterizado quando a temperatura variou $0,1^{\circ} \mathrm{C} / \mathrm{min}$. $\mathrm{O}$ de fim de pega foi obtido quando a temperatura máxima foi atingida.

O calorímetro pseudoadiabático foi confeccionado com um recipiente de isopor, proporcionando um isolamento da amostra do meio externo (Figura 2). Para medir a variação da temperatura utilizou-se um termômetro de precisão de $0,1^{\circ} \mathrm{C}$ com um termopar do tipo k (Cromel-Alumel) acoplado.

Figura 2 - Calorímetro pseudoadiabático

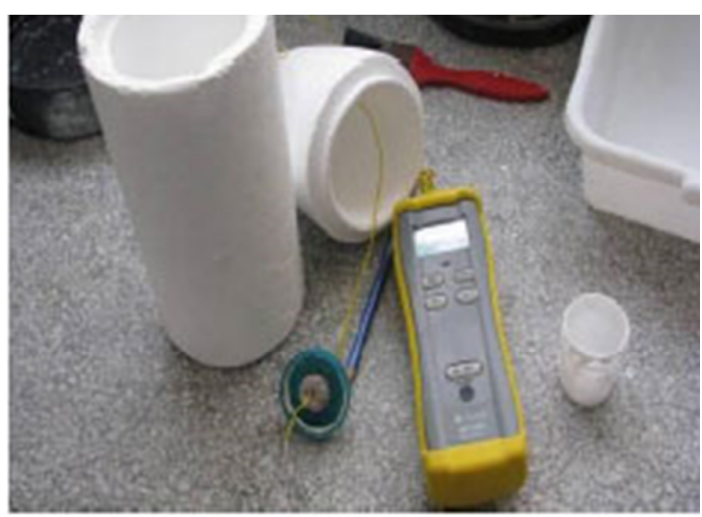

\section{RESULTADOS}

Os resultados da caracterização do gesso e do resíduo estão apresentados no Quadro 2.

Quadro 2 - Caracterização do gesso e do resíduo

\begin{tabular}{|l|c|c|}
\hline Propriedade & Gesso & Resíduo \\
\hline Módulo de finura & 0,098 & 1,071 \\
\hline Massa unitária $\left(\mathrm{kg} / \mathrm{m}^{3}\right)$ & 731,51 & 649,38 \\
\hline Consistência normal & 0,45 & 0,60 \\
\hline
\end{tabular}


O módulo de finura determinado para o gesso e o resíduo indica que ambos são finos, pois os resultados foram menores que 1,1, de acordo com a NBR 13207 (ABNT, 1994).

A consistência normal do resíduo foi obtida utilizando $100 \%$ de resíduo calcinado mais água. Para possibilitar os ensaios da mistura de gesso com resíduo, utilizou-se uma consistência normal maior que a do gesso. Ao invés de 0,45 , fixou-se a relação água/materiais secos em 0,6 .

As misturas com $10 \%$ e $50 \%$ de resíduo, com e sem aditivo, apresentaram melhor trabalhabilidade para moldagem dos corpos de prova, apresentado um melhor acabamento com menos porosidade. As misturas com $90 \%$ de resíduo, com e sem aditivo, e $100 \%$ de resíduo, com aditivo, se mostraram com um acabamento ruim e uma trabalhabilidade comprometida. No caso da mistura com $100 \%$ de resíduo sem aditivo, não houve trabalhabilidade suficiente para moldagem dos corpos de prova (Figura 3).

\section{Figura 3 - Tentativa de moldagem de corpos de prova com $100 \%$ de resíduo sem} aditivo retardador de pega

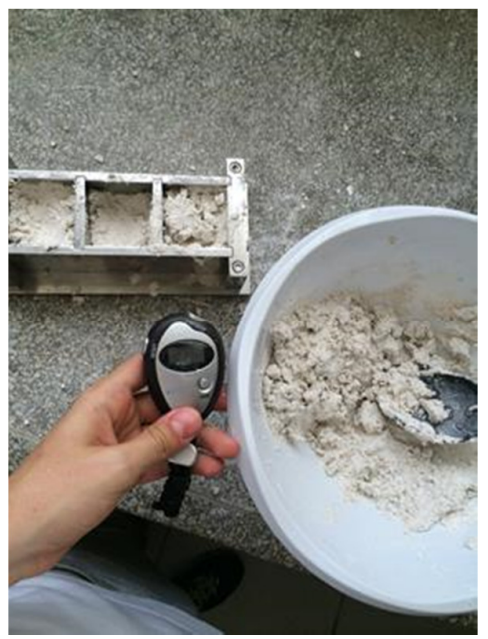

Os resultados de dureza e resistência à compressão das misturas de gesso com substituição, em massa, por diferentes porcentagens de resíduo, com e sem aditivo retardador de pega - citrato de sódio, estão no Quadro 3.

As misturas com e sem aditivo mantiveram a dureza próxima a do gesso ( $0 \%$ de resíduo). Apenas a mistura com $100 \%$ de resíduo e aditivo retardador de pega apresentou uma queda de $4 \%$.

Na resistência à compressão as misturas de gesso com e sem aditivo e a mistura com $10 \%$ de resíduo sem retardador de pega apresentaram resistência dentro do critério recomendado pela NBR 13207 (ABNT, 1994), de 8,4 MPa; embora esta norma não regulamente misturas com resíduos. Observou-se que quanto maior a porcentagem de resíduo, maior a porosidade e menor a resistência. Constatou-se ainda que o uso do citrato de sódio fez diminuir a resistência à compressão (Figura 4).

As misturas com $90 \%$ e $100 \%$ de resíduo mostraram-se inviáveis para a relação água/materiais secos adotada. 
Quadro 3 - Propriedades das misturas de gesso e resíduo com e sem aditivo retardador de pega

\begin{tabular}{|l|c|c|}
\hline Misturas & Dureza (u.s.c.) & Resistência à compressão (MPa) \\
\hline $0 \%$ de resíduo sem aditivo & 96,22 & 22,00 \\
\hline $0 \%$ de resíduo com aditivo & 96,45 & 17,33 \\
\hline $10 \%$ de resíduo sem aditivo & 95,33 & 12,33 \\
\hline $10 \%$ de resíduo com aditivo & 95,56 & 6,33 \\
\hline $50 \%$ de resíduo sem aditivo & 98,89 & 5,33 \\
\hline $50 \%$ de resíduo com aditivo & 94,33 & 4,67 \\
\hline 90\% de resíduo sem aditivo & 96,55 & 1,33 \\
\hline 90\% de resíduo com aditivo & 95,89 & 1,67 \\
\hline $100 \%$ de resíduo sem aditivo & $*$ & $*$ \\
\hline $100 \%$ de resíduo com aditivo & 92,56 & 1,00 \\
\hline
\end{tabular}

*Não houve trabalhabilidade suficiente para moldar os corpos de prova

Figura 4 - Resistência à compressão das misturas com e sem aditivo retardador de pega

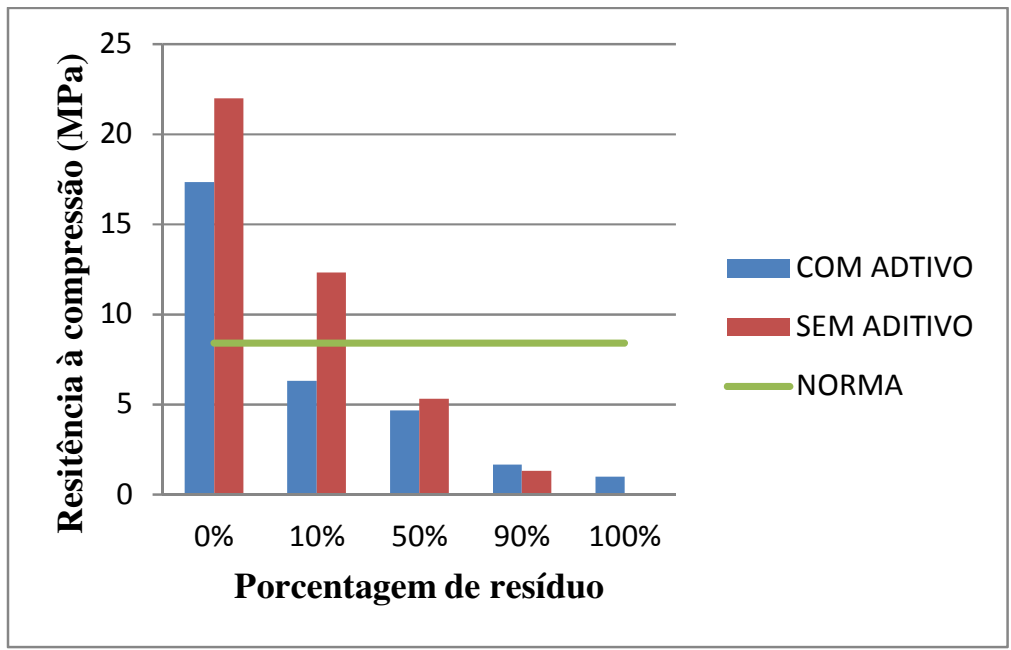

Com o calorímetro obteve-se as curvas de calor de hidratação das amostras sem e com aditivo retardador de pega (Figuras 5 e 6 ).

As misturas com resíduo que não utilizaram retardador de pega tiveram variabilidade pequena de tempo de fim de pega. Estes tempos estão indicados próximos às curvas de calor de hidratação (Figura 5). Na medida em que se aumenta o percentual de resíduo a temperatura máxima diminui. Observa-se, também, que a curva característica de hidratação em formato de "S" não existe nas misturas com 90\% e 100\% de resíduo, indicando que a maior parte do processo de hidratação já ocorreu aos 5 minutos.

Com a adição do citrato de sódio constatou-se um aumento no tempo de utilização das misturas com 0\%, 10\% e 50\% de resíduo (Figura 6). As misturas com $90 \%$ e $100 \%$ não apresentaram variabilidade significativa, mas se apresentaram com o tempo de fim de 
pega menor. A curva característica de hidratação em formato de " $S$ " que não existia apresentou tendência a se formar nas misturas com $90 \%$ e $100 \%$ de resíduo, indicando que o processo de hidratação foi retardado, mas não houve aumento do tempo de utilização, calculado pela subtração entre os tempos de pega final e inicial.

Aos 5 minutos (4 minutos de mistura mais 1 minuto de preparo da amostra) a temperatura de todas as misturas apresentou variação de $0,1^{\circ} \mathrm{C} / \mathrm{min}$, indicando que o tempo de início de pega foi menor que este. Sendo assim, para calcular o tempo de utilização, este tempo foi considerado igual a 5 minutos para todas as misturas.

Figura 5 - Curva de calor de hidratação das misturas de gesso e resíduo sem aditivo retardador de pega

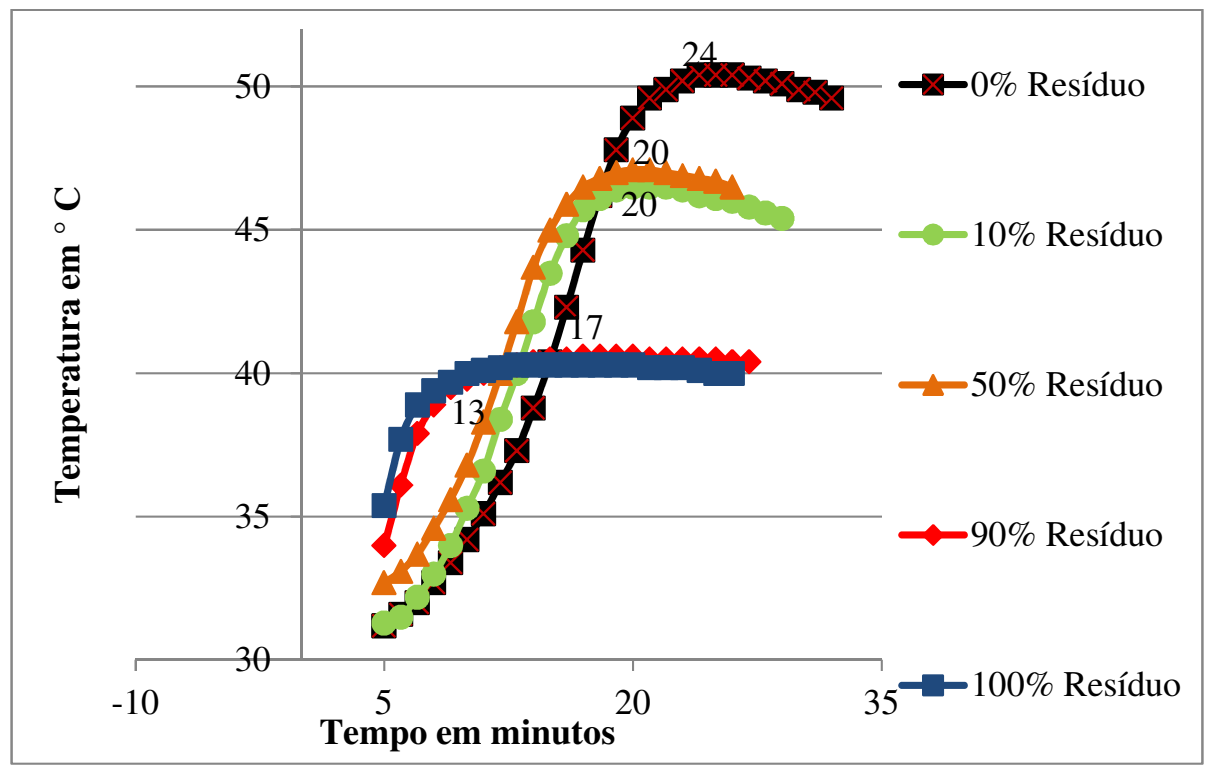

Figura 6 - Curva de calor de hidratação das misturas de gesso e resíduo com aditivo retardador de pega

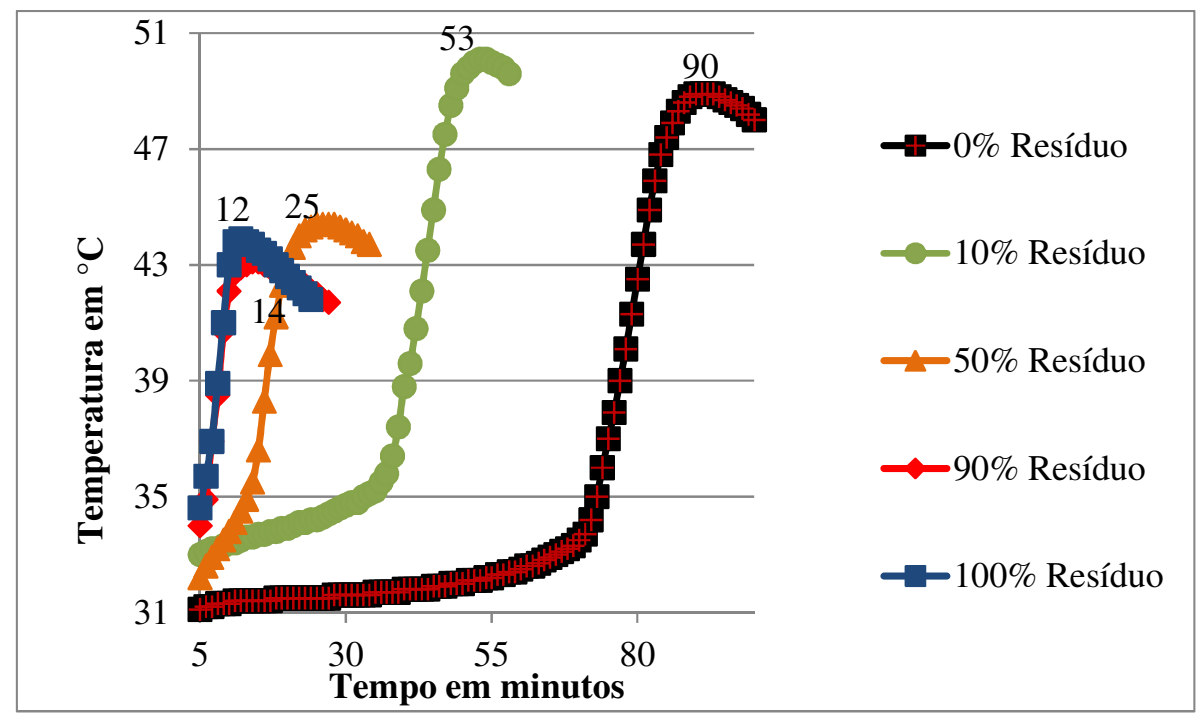


A mistura com $50 \%$ de resíduo e com citrato de sódio apresentou o mesmo tempo de utilização da pasta de gesso sem retardador de pega (Figura 7), o que indica a viabilização do seu uso em obra.

Figura 5 - Tempo de fim de pega das misturas de gesso e resíduo com e sem aditivo retardador de pega

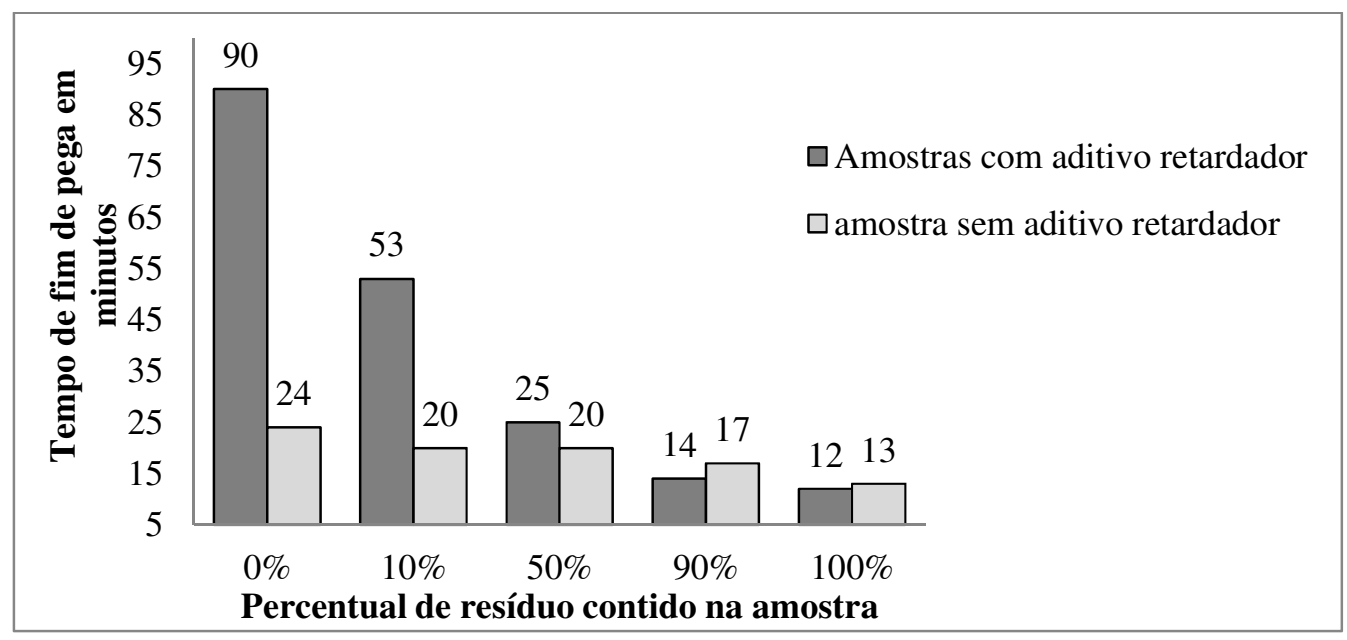

\section{CONCLUSÕES}

$\mathrm{O}$ citrato de sódio diminuiu a resistência à compressão de todas as misturas.

O tempo de utilização das misturas com $0 \%, 10 \%$ e 50\% de resíduo aumentaram com a adição do retardador de pega, mas não houve variabilidade significativa nas misturas com $90 \%$ e $100 \%$.

A mistura com $50 \%$ de resíduo e com o retardador de pega apresentou o mesmo tempo de utilização da pasta de gesso sem o aditivo, viabilizando seu uso em obra.

\section{AGRADECIMENTOS}

Agradeço a Escola Politécnica de Pernambuco pela oportunidade de desenvolver esta pesquisa fornecendo uma bolsa de iniciação científica.

\section{REFERÊNCIAS}

ALVES, B.C.A; CAVALCANTI, R.A.A.; ROMANO, R.C.O.; JOHN, V.M.; PÓVOAS, Y.V. Interferência do citrato de sódio na calorimetria da pasta de gesso. In: Encontro Nacional de Tecnologia do Ambiente Construído. Entac, 2012. CD-ROM. Juiz de Fora, 2012.

ASSOCIAÇÃO BRASILEIRA DE NORMAS TÉCNICAS. MB 3468. Gesso para construção: determinação das propriedades físicas do pó. Rio de Janeiro, 1991.

MB 3469. Gesso para construção: determinação das propriedades físicas da pasta. Rio de Janeiro, 1991.

MB 3470. Gesso para construção: determinação das propriedades mecânicas.

Rio de Janeiro, 1991. 
NBR 12775. Placas lisas de gesso para forro - Determinação das dimensões e propriedades físicas. Rio de Janeiro, 1992.

NBR 13207. Gesso para construção civil: Especificação. Rio de Janeiro, 1994.

AYRES, M. Indústria de construção civil deve crescer 2,8\% em 2014. Revista Exame. Dezembro de 2013. Disponível em: $<$ http://exame.abril.com.br/economia/noticias/industria-brasileira-de-construcao-civildeve-crescer-2-8-em-2014>. Acesso em: 28 de março de 2014.

CAVALCANTI, R.A.A.; ALVES, B.C.A; ROMANO, R.C.O.; JOHN, V.M.; PÓVOAS, Y.V. Composição granulométrica do resíduo de gesso influencia nas propriedades do revestimento interno de parede. In: Encontro Nacional de Tecnologia do Ambiente Construído. ENTAC, 2012. CD-ROM. Juiz de Fora, 2012.

CINCOTTO, M.A; HINCAPIÉ, A.M. Seleção de substâncias retardadoras do tempo de pega do gesso de construção civil. Boletim técnico BT/PCC/184 da Escola Politécnica da USP-Departamento de engenharia de construção civil - Universidade de São Paulo - São Paulo. 1997.

CINCOTTO, M.A.; JOHN, V.M. Materiais de construção civil e princípios de ciências e engenharia de matérias. volume $1.2^{\circ}$ edição. 2010.

CONSELHO NACIONAL DE MEIO AMBIENTE. CONAMA. Resolução n. 431, de 24 de maio de 2011. Altera o art. $3^{\circ}$ da Resolução n. 307, de 5 de julho de 2002, estabelecendo nova classificação para o gesso. Diário Oficial da República Federativa do Brasil.

DEPARTAMENTO NACIONAL DE PRODUÇÃO MINERAL - DNPM. Sumário mineral, 2013.

GUSMÃO, A.D. Manual de Gestão de Resíduos da Construção Civil. 1. ed. Camaragibe/PE: CCS Editora e Gráfica, 2008. 140 p.

PINHEIRO, S.M.M. Gesso reciclado: avaliação de propriedades para uso em componentes. Tese de doutorado em engenharia civil. Universidade estadual de Campinas. Campinas. 2011.

RIBEIRO, A.S., SANTOS, V.A.; BENACHOUR, M.; de MELO, D. C. P.; CAVALCANTI, D. E. S. Potencial alternativo na reciclagem de resíduos de gesso na construção civil. Revista Pernambucana de Tecnologia. v.1, n.1, outubro de 2013. p.57-71.

SCHIMITZ, I.B.T.A.; PÓVOAS, Y.V. 2009. Análise de desempenho do revestimento de gesso com adição de seu resíduo gerado em obra. In:IV Encontro Latino-Americano sobre edificações e comunicações sustentáveis. Anais. Recife. 2009. 